\title{
ANALISA DETERMINAN PENGETAHUAN DAN SIKAP REMAJA PUTRI TENTANG DISMENORHEA
}

\author{
Siti Nurjanah ${ }^{1}$ \\ ${ }^{1}$ Universitas Muhammadiyah Semarang \\ E-mail: sitinurjanah@unimus.ac.id
}

\begin{abstract}
ABSTRAK
Dismenorea masih menjadi masalah kesehatan wanita, padahal tingkat derajat nyeri seseorang berbeda, sehingga dismenorea ini adalah bukan masalah yang serius jika seseorang mengetahui dan dapat menyikapinya dengan baik. Studi pendahuluan yang dilakukan di SMP IT Muhammadiyah Miri Sragen didapatkan 7 siswi berpengetahuan cukup, 3 bepengetahuan kurang dan 7 siswi menyatakan tidak setuju dengan dismenorea dan 3 lainnya menyatakan setuju tentang

dismenorea. Mereka kurang mendapatkan informasi tentang dismenorea sehingga perlu dilakukan penyuluhan tentang dismenorea. Penelitian ini dilakukan untuk mengetahui gambaran pengetahuan dan sikap tentang Dismenorhea di SMP IT Muhammadiyah Miri Sragen. Jenis penelitian ini adalah penelitian deskriptif, dengan pendekatan cross sectional. Sampel sebanyak 35 responden, teknik sampling yang digunakan adalah Acidental Sampling. Hasil penelitian menunjukkan bahwa sebagian besar pengetahuan responden tentang dismenorhea berpengetahuan baik yaitu sebanyak 21 orang $(60 \%)$. Sedangkan sikap responden terhadap dismenorhea sebagian besar memiliki sikap positif yaitu sebanyak 31 responden $(88,6 \%)$. Berdasarkan hasil penelitian didapatkan hasil gambaran siswi SMP IT Muhammadiyah Miri, Sragen berpengetahuan baik dan bersikap positif terhadap dismenorhea.
\end{abstract}

Kata Kunci: Pengetahuan; Sikap; Dismenorhea

\section{ANALYSIS OF KNOWLEDGE AND ADOLESCENT DETERMINANTS ABOUT DISMENORHEA}

\begin{abstract}
Dysmenorrhea still become a women's health problems, meanwhile the degree of pain level in each person is different. Dysmenorrhea will be handled if we know how to treat well. The pleminary study was held at SMP IT Muhammadiyah Miri Sragen, and gained 7 student are knowledgeable enough, 3 student are less knowledgeable and 7 student did not agree with dysmenorrhea and 3 other disagreed about dysmenorrhea. It was because of the lack of information about dysmenorrhea, so counselling is needed. The purpose of this study was to determine the knowledge and attitude of dysmenorrhea at SMP IT Muhammadiyah Miri Sragen. This study was descriptive study with cross-sectional approach. Samples were 35 respondents, the sampling technique used was Acidental Sampling. The esult shows that most respondents who have good understanding is 21 people $(60 \%)$. While 31 respondents $(88.6 \%)$ have positive attitude regarding dysmenorrhea. Based on the research results, female stuedents at SMP IT Muhammadiyah Miri- Sragen have good knowledge and positive attitude towards dysmenorrhoea.
\end{abstract}

Keywords: Attitude, Dysmenorrhoea, Knowledge. 


\section{Pendahuluan}

Masa remaja adalah proses tumbuh menuju ke arah kematangan termasuk dalam kematangan mental, emosional, sosial, dan fisik. Masa ini ditandai dengan kematangan organ seksual dan mampu untuk bereproduksi, dimana salah satu tanda pubertas seorang perempuan adalah menstruasi pertama atau menarche (Janiwarty dan Pieter, 2013). Salah satu masalah yang timpul pada saat masa pubertas remaja putri adalah disminorhea. disminordihadapi adalah disminore yang hampir setiap bulan mereka hadapi. Disminore adalah nyeri pada daerah panggul akibat menstruasi dan produksi zat prostaglandin (Andriyani, 2013).

Angka kejadian disminorhea di dunia cukup tinggi, 50\% wanita di dunia menderita disminore dalam sebuah siklus menstruasi. Hampir 90\% wanita di Amerika Serikat mengalami disminore dan $10-15 \%$ diantaranya mengalami disminore berat, yang menyebabkan mereka tidak mampu melakukan kegiatan apapun dan ini akan menurunkan kualitas hidup pada individu masing-masing. Perempuan di Amerika Serikat diperkirakan kehilangan 1,7 juta hari kerja setiap bulan akibat dismenore (Calis, 2011). Di Pakistan diperkirakan $57 \%$ pelajar yang mengalami disminore mempunyai efek terhadap pekerjaan mereka (Tariq, 2009).

Di Indonesia angka kejadian disminore tipe primer adalah sekitar 54,89\% sedangkan sisanya penderita dengan disminore sekunder. Disminore terjadi pada remaja dengan prevalensi berkisar antara $43 \%$ hingga 93\%, dimana sekitar $74-80 \%$ remaja mengalami disminore ringan, sementara angka kejadian endometriosis pada remaja dengan nyeri panggul diperkirakan 25-38\%, sedangkan pada remaja yang tidak memberikan respon positif terhadap penanganan untuk nyeri haid, endometriosis ditemukan pada $67 \%$ kasus di laparoskopi (Hestiantoro dkk, 2012).

Penelitian yang dilakukan Nafiroh (2013) tentang gambaran pengetahuan remaja putri terhadap disminore pada siswi putri di MTS NU Mranggen Kabupaten Demak dapat disimpulkan berdasarkan hasil wawancara terhadap 10 siswi MTs NU Mranggen Kabupaten Demak, ada 7 siswi yang kurang tahu tentang disminore, 1 siswi yang cukup tahu tentang dismenore dan 2 siswi yang sudah tahu tentang disminore. Hal itu terjadi kemungkinan dari tidak adanya pendidikan kesehatan reproduksi di MTs NU Mranggen Kabupaten Demak.

Hasil studi pendahuluan pengetahuan tentang Dismenorea pada remaja putri di SMP IT Muhammadiyah Miri dari 10 siswi putri didapatkan sebanyak 7 siswi bepengetahuan cukup tentang dismenorea, sebanyak 3 siswi kurang mengetahui tentang dismenorea. Hal itu terjadi karena tidak adanya pendidikan kesehatan reproduksi secara khusus tentang dismenorea, 
karena meskipun ada mata pelajaran biologi tetapi hanya membahas tentang anatomi tumbuhan dan hewan beserta fungsinya. Dari data tersebut, maka pendidikan kesehatan atau penyuluhan kesehatan reproduksi tentang dismenorea sangat penting untuk dilakukan agar mereka dapat menanganinya dengan baik sehingga aktivitas mereka tidak terganggu saat menstruasi karena dismenorea. Berdasarkan latar belakang di atas perlu dilakukan penelitian tentang "Gambaran Pengetahuan Dan Sikap Tentang Dismenorhea Di SMP IT Muhammadiyah Miri Sragen”.

\section{Tinjauan Teoritis}

1. Disminorhea

Menurut M. Anwar (2014), disminore adalah nyeri saat haid, biasanya dengan rasa kram dan terpusat di abdomen bawah. Keluhan nyeri haid dapat terjadi bervariasi mulai dari yang ringan sampai berat. Nyeri haid yang dimaksud adalah nyeri haid berat sampai menyebabkan perempuan tersebut datang berobat ke dokter atau mengobati dirinya sendiri dengan obat anti nyeri. gejala disminore terdiri dari nyeri abdomen bagian bawah kemudian menjalar ke daerah pinggang dan paha, dan terkadang disertai mual, muntah, sakit kepala dan diare (Manuaba 2011). Jenis disminorhea adalah disminorhea primer yaitu nyeri haid tanpa ditemukan keadaan patologi pada panggul. Disminore primer berhubungan dengan siklus ovulasi dan disebabkan oleh kontraksi myometrium sehingga terjadi iskemia akibat adanya prostaglandin yang diproduksi oleh endometrim fase sekresi. Disminorhea sekunder nyeri haid yang berhubungan berbagai keadaan patologis di organ genitalia, misalnya endrometriosis, adenomiosis, mioma uteri, stenosis serviks, penyakit radang panggul, perlekatan panggul,atau irritable bowel syndrome (M. Anwar, 2014).

2. Pengetahuan

Pengetahuan merupakan domain yang sangat penting untuk terbentuknya tindakan seseorang (over behavior). Pengetahuan diperlukan sebagai dukungan dalam menumbuhkan rasa percaya diri maupun sikap dan perilaku setiap hari, sehingga dapat dikatakan bahwa pengetahuan merupakan fakta yang mendukung tindakan seseorang (Notoatmodjo, 2010). Klasifikasi pengetahuan menurut Notoadmodjo (2010) adalah dari tahu, memahami, aplikasi, analisis, sintesis, dan tahap terakhir adalah evaluasi. Proses mengadopsi perbuatan dalam diri seseorang tersebut akan terjadi proses sebagai berikut: kesadaran, tertarik, evaluasi, mencoba, adaptasi. Faktor-faktor yang mempengaruhi pengetahuan adalah pendidikan, informasi, sosial budaya dan ekonomi, lingkungan, 
pengalaman, serta usia.

3. Sikap

Sikap adalah reaksi atau respon seseorang yang masih tertutup terhadap suatu stimulus atau obyek (Notoatmodjo dalam Wawan, 2010). Melalui sikap dapat memahami proses kesadaran yang menentukan tindakan nyata dan tindakan yang mungkin dilakukan individu dalam kehidupan sosial. Sikap terdiri dari berbagai tingkatan yaitu: menerima (receiving), merespon (responding), menghargai (valuing), dan bertanggung jawab (responsible). Faktor-faktor yang mempengaruhi sikap terhadap objek sikap antara lain (Wawan \& Dewi, 2010): pengalaman pribadi, pengaruh orang lain yang dianggap penting, pengaruh kebudayaan, media massa, lembaga pendidikan dan agama, serta faktor emosional.

4. Sikap dan Perilaku Kesehatan

Menurut Green (1980) dalam Notoatmodjo (2012), perilaku individu dan masyarakat dipengaruhi oleh 3 faktor utama yaitu: faktor predisposisi (predisposing factors), yaitu faktor-faktor yang mempermudah terjadinya perilaku seseorang meliputi pengetahuan, sikap, nilai dan keyakinan, faktor pemungkin (Enabling factors), terwujud dalam bentuk lingkungan fisik seperti ketersediaan fasilitas kesehatan, keterjangkauan fisilitas kesehatan dan keterampilan petugas kesehatan (Mubarak, 2011). Faktor penguat (Reinforcing factors), yaitu faktor-faktor yang mendorong terjadinya perilaku meliputi dukungan keluarga dan petugas kesehatan.

\section{Metode Penelitian}

Metode yang digunakan adalah survey melalui wawancara menggunakan kuesioner metode pendekatan cross sectional. Penelitian dilakukan di SMP IT Muhammadiyah Miri Sragen dilaksanakan pada bulan Januari 2018. Sampel penelitian ini adalah seluruh populasi yaitu siswi kelas IX SMP IT Muhammadiyah Miri Sragen berjumlah 35 orang. Alat pengumpulan data dalam penelitian ini adalah menggunakan kuesioner dihitung berdasarkan skor. Pertanyaan tersebut terdiri dari kuesioner A tentang pengetahuan siswi tentang dismenorhea dan kuesioner B tentang sikap tentang dismenorhea. Analisis data menggunakan analisis univariat untuk mendiskripsikan pengetahuan dengan sikap menggunakan minimum dan maksimum rata-rata dan sikap dan tabel distribusi frekuensi. Untuk distribusi frekuensi menggunakan rumus penentuan besarnya prosentase. 


\section{Hasil Penelitian}

Tabel 1 Distribusi Responden berdasarkan Umur Siswi Kelas IX SMP IT Muhammadiyah Miri Sragen

\begin{tabular}{ccc}
\hline Umur & Frekuensi & Presentase (\%) \\
\hline 13 & 5 & 14,3 \\
14 & 13 & 37,1 \\
15 & 17 & 48,6 \\
\hline Total & 35 & 100 \\
\hline
\end{tabular}

Berdasarkan Tabel 1 didapatkan hasil penelitian bahwa sebagian besar umur responden yaitu 15 tahun $(48,6 \%)$.

Tabel 2 Distribusi Responden berdasarkan Pengetahuan Responden tentang Dismenorhea

\begin{tabular}{ccc}
\hline Pengetahuan Responden & Frekuensi & Persentase (\%) \\
\hline Baik & 21 & 60 \\
Cukup & 4 & 11,4 \\
Kurang & 10 & 28,6 \\
\hline Total & 35 & 100 \\
\hline
\end{tabular}

Berdasarkan tabel 2 didapatkan hasil penelitian bahwa sebagian besar responden berpengetahuan baik yaitu sebanyak 21 orang $(60 \%)$.

Tabel 3 Distribusi Responden berdasarkan Sikap terhadap Dismenorhea

\begin{tabular}{lrr}
\hline Sikap Responden & Frekuensi & Presentase (\%) \\
\hline Positif & 31 & 88,6 \\
Negatif & 4 & 11,4 \\
\hline Total & 35 & 100 \\
\hline
\end{tabular}

Berdasarkan Tabel 3 diperoleh sebagian besar data bahwa Responden yang bersikap positif sebanyak 31 responden $(88,6 \%)$.

\section{Pembahasan}

Sebagian besar siswa di SMP IT Muhammadiyah Miri Sragen berjenis kelamin perempuan $(63,55 \%)$ dan pengetahuan mereka tentang dismenorhea masih kurang, karena meskipun ada mata pelajaran biologi tetapi hanya membahas tentang anatomi reproduksi beserta fungsinya tidak membahas tentang kesehatan reproduksi khususnya tentang dismenorhea. Tidak adanya pendidikan kesehatan tentang kesehatan reproduksi gangguan menstruasi dari tenaga kesehatan, intitusi itu sendiri, maupun kesadaran dari siswi itu sendiri untuk mencari informasi tentang dismenorhea merupakan faktor utama kurangnya pengetahuan dan sikap tentang dismenorhea. 
1. Pengetahuan Responden tentang Disminorhea

Berbagai informasi dari banyak pihak luar penting untuk menambah pengetahuan remaja putri tentang penanganan dismenore baik dari media, orang tua, tenaga kesehatan, maupun dari teman. Informasi memberikan pengaruh terhadap pengetahuan seseorang. Seseorang yang mempunyai banyak informasi akan mempunyai pengetahuan yang luas (Notoatmodjo, 2012). Berdasarkan hasil penelitian pada tabel 2 distribusi kategori pengetahuan diperoleh jumlah responden terbanyak yang memiliki pengetahuan baik sebanyak 21 orang (60\%), pengetahuan kurang 10 orang (28,6\%), dan pengetahuan cukup 4 orang orang $(11,4 \%)$. Hasil data penelitian ini menggambarkan remaja putri terbanyak memiliki pengetahuan baik tentang dismenore. Sesuai dengan teori menurut Notoatmodjo, 2012 bahwa pengetahuan merupakan hasil dari tahu, dan ini terjadi setelah orang melakukan pengindraan terhadap suatu objek tertentu. Pengindraan terjadi melalui pancaindra manusia, yakni indra penglihatan, pendengaran, penciuman, rasa, dan raba. Menurut hasil penelitian Nafiroh (2013) diketahui bahwa mayoritas responden memiliki pengetahuan kurang tentang dismenore yaitu sebanyak 36 siswi (78,3\%) berbeda dengan penelitian ini bahwa $60 \%$ responden memiliki pengetahuan yang baik tentang disminorhea. Teori Notoatmodjo, 2012 pendidikan, umur, informasi, dan pengalaman merupakan faktor-faktor yang mempengaruhi pengetahuan. Responden remaja putri dalam penelitian ini masih berada pada remaja tahap menengah rata-rata berumur 15 tahun, remaja putri harus banyak mencari informasi dari berbagai pihak selain dari media ada juga petugas kesehatan, orang tua, dan teman yang dapat memberikan informasi yang berguna dan dapat menambah wawasan pengetahuan remaja putri tentang dismenore. Faktor yang mempengaruhi responden berpengetahuan baik tentang dismenorhea karena pengetahuan dari responden dipengaruhi oleh pengalaman saat diberikan penyuluhan oleh tenaga kesehatan. Hal ini sesuai dengan teori Wawan \& Dewi (2010) yang menyatakan bahwa "Pengalaman pribadi juga dapat digunakan sebagai upaya memperoleh pengetahuan. Hal ini dilakukan dengan cara mengulang kembali pengalaman yang diperoleh dalam memecahkan permasalahan yang dihadapi pada masa yang lalu”.

Hasil penelitian Paramita, 2010 menunjukan bahwa tingkat pengetahuan tentang dismenore pada siswi sebagain besar berada pada kategori cukup yaitu 7 sebanyak 50 orang dengan perilaku penanganan dismenore sebagaian besar berada pada kategori baik yaitu sebanyak 40 orang. Ini berarti bahwa semakin baik tingkat pengetahuan seseorang maka semakin baik sikapnya. 
2. Sikap Responden tentang Disminorhea

Berdasarkan hasil penelitian pada tabel 3 distribusi kategori sikap penanganan dismenore diperoleh jumlah responden terbanyak yang memiliki sikap positif sebanyak 31 orang $(88,6 \%)$ dan responden bersikap negatif sebanyak 4 orang $(11,4 \%)$. Hasil data penelitian ini menggambarkan remaja putri terbanyak memiliki sikap penanganan dismenore yang baik. Menurut penelitian Mahavash (2012) bahwa dari 133 responden didapatkan sebanyak 54,9\% memiliki sikap baik dalam mengatasi dismenore. Perilaku penanganan dismenore yang dilakukan remaja putri tergolong baik karena baiknya pengetahuan yang diperoleh remaja putri tentang dismenore. Hal ini sesuai dengan teori menurut Fitriani, 2011 yang menyatakan bahwa dari pengalaman dan penelitian terbukti bahwa sikap yang didasari oleh pengetahuan akan lebih langgeng dari pada sikap yang tidak didasari oleh pengetahuan. Kurangnya sikap remaja putri dalam menangani dismenore ketika menstruasi terjadi karena kurangnya kesadaran remaja putri mengetahui penyebab, gejala, dan cara penanganannya, sehingga remaja putri tidak pernah memeriksanya ke petugas kesehatan. Selaian itu kurangnya ketertarikan untuk mencari berbagai informasi mengenai dismenore sehingga remaja putri kurang mengetahui perilaku penanganan dismenore yang baik. Dapat disimpulkan dari analisis di atas menunjukan adanya sikap positif tentang dismenorhea pengaruh dari penyuluhan yang dapat mengubah atau meningkatkan sikap terhadap dismenorhea pada siswi.

\section{Kesimpulan}

Pengetahuan siswi kelas IX SMP IT Muhammadiyah Miri Sragen tentang dismenorhea sebagian besar baik dan sebagian besar besikap positif

\section{Saran}

Bagi tenaga kesehatan khususnya puskesmas, dapat melakukan kerjasama dengan pihak-pihak sekolah baik tingkat pertama (SMP) maupun tingkat atas (SMA) untuk memberikan penyuluhan tentang kesehatan reproduksi pada remaja khususnya tentang dismenorea dan di tekankan pada materi pencegahan dismenorhea. Masyarakat memiliki kesadaran diri untuk lebih aktif dalam hal mendapatkan informasi kesehatan reproduksi mengenai dismenorea baik melalui media massa maupun petugas kesehatan. 


\section{Daftar Pustaka}

Andriyani, A. (2013). Panduan Kesehatan Wanita. Solo: As-Salam Group

Anwar, M. (2014). Ilmu Kandungan. Jakarta: PT Bina Pustaka Sarwono Prawirohardjo.

Calis Karim Anton. (2011). Dysmenorrhea. Available. Diakses 20 Februari 2018 dari http://emedicine.medscape.com/article/253812-overview.

Dewi dan wawan (2011) Teori dan Pengukuran Pengetahuan, Sikap dan Perilaku Manusia. Yogyakarta: Nuha Medika.

Hestiantoro, A., Natadisastra, M.,Sumapraja, K., Wiweko, B., Pramata,G., Situmorang, H., \& Kemal, A. (2012). Best Practices On Imperial. Jakarta: Sagung Seto.

Janiwarty, B dan Pieter, H. Z. (2013). Pendidikan Psikologi untuk Bidan Suatu Teori dan Terapannya. Yogyakarta: Rapha Publishing.

Mahavash et. al. (2012). The Effect of Physical Activity on Primary Dysmenorrhea of Female University students. World Applied Scieces Journal 17 (10): 1246- 1252.

Machfoedz. 2009. Teknik Membuat Alat Ukur Penelitian Bidang Kesehatan, Keperawatan, dan Kebidanan, Jakarta : Rineka Cipta

Manuaba. (2011). Ilmu Kebidanan Penyakit Kandungan dan Keluarga Berencana untuk Pendidikan Bidan. Jakarta: EGC.

Nafiroh, D. (2013). Gambaran Pengetahuan Remaja tentang Disminore pada Siswa Putri di MTs NU Mranggen Kabupaten Demak. Jurnal ilmiah kebidanan, Vol.4 No.1

Notoatmodjo. (2012). Promosi Kesehatan dan Perilaku Kesehatan. Jakarta: Rineka Cipta.

Notoatmodjo. (2010). Ilmu Perilaku Kesehatan. Jakarta: PT Rineka Cipta.

Paramita.(2010). Hubungan Tingkat Pengetahuan Tentang Dismenorea dengan Perilaku Penangan Dismenorea pada Siswi SMK YPKK I Sleman Yogyakarta. Karya Tulis Ilmiah, Program Studi D IV Kebidanan Fakultas Kedokteran Universitas Sebelas Maret, Surakarta.

Tariq, Nabia, (2009). Impact and Healthcare-seeking Behaviour of Premenstrual Symptoms and Dysmenorrhea. Diakses 22 Februari 2018 dari http://BJMP1209Tariq/ 